\title{
INFLUÊNCIAS DOS MÉTODOS DE COCÇÃO NA PRESERVAÇÃO DE COMPOSTOS BIOATIVOS NA BETA VULGARIS, L.
}

\section{COOKING METHODS INFLUENCE ON BEETROOT BIOACTIVE COMPOUNDS PRESERVATION}

\author{
${ }^{1}$ Mauricio Marangon, Luiz ${ }^{2}$ Hernandes Martins, Adriana ${ }^{3}$ Schlemer Kramer, Luiza \\ Caroline ${ }^{4}$ Mirante Da Silva, Juliana Aparecida

\begin{abstract}
${ }^{1}$ Nutricionista Centro Universitário Fundação Assis Gurgacz - FAG. ${ }^{2}$ Nutricionista Especialista, Docente do Curso de Nutrição, Centro Universitário Fundação Assis Gurgacz (FAG). ${ }^{3}$ Acadêmica Universidade Tecnologica Federal do Paraná (UTFPR). ${ }^{4}$ Acadêmica Universidade Tecnologica Federal do Paraná (UTFPR).

* Autor correspondente: adrihernandesm@gmail.com, https://orcid.org/0000-0001-9718-5846
\end{abstract}

\begin{abstract}
RESUMO
Introdução: Vive-se em uma época em que o papel dos alimentos na manutenção da vida e da saúde no cotidiano, vem sendo cada vez mais estudados, pelos benefícios por eles concebidos. Por este motivo os compostos bioativos vem sendo cada vez mais utilizados, um deles é a betalaina. Este composto está presente na Beta vulgaris, L. (beterraba), cogumelos, e algumas flores. Assim como vários outros compostos fenólicos, antocianinas, carotenoides, e o seu estudo em relação a saúde do consumidor. Como a beterraba é uma hortaliça complexa nestes componentes, e muito consumida em diferentes formas culinárias. Objetivo: Avaliar os métodos de cocção em airfyrer, micro-ondas e cozimento convencional em panela. Metodologia: Assim, verificando a influência de diferentes métodos de cocção, quanto ao tempo de preparo, alterações em fator antioxidante, compostos fenólicos, e a preferência de cada cocção, a qual por teste de preferência foi definida o melhor consumo, Resultados: assim sobressaindo as provenientes da preparação em micro-ondas e panela. E por análises de compostos fenólicos, a maior concentração em preparações que passam por tratamento térmico. Mas em contrapartida, uma maior ação antioxidante na beterraba in natura, demonstrando a susceptibilidade em seus compostos em alterar diante ao meio exposto. Conclusão: Sendo de grande importância o seu consumo em variadas formas de cocção em preparações gastronômicas para um aproveitamento de todos os seus compostos nela expressa.
\end{abstract}

Palavras-chave: Cocção, Compostos Bioativos, Betalainas, Beterraba

\section{ABSTRACT}

Introduction: We live in a period where food has a huge importance for our daily, for life maintenance and for the health. Due food benefits, investigations is increasingly studying. For this reason the bioactive compounds become more useful and one of them its called betalain. This compound is founded on the beetroot, mushrooms and some flowers. Like another phenolic compounds, antocianines, carotenoids and their studies about consumer health. Objective: As the beetroot is considered a complex vegetable due its compounds, and a vegetable consumed in a different ways, was necessary evaluate the several ways of beetroot preparation, such as, air 
fryer, microwave and the conventional cooking. Methodology: Testing different cooking methods and its preparation time, antioxidants alterations and phenolic compounds. Results: Through preference tests was possible to aim which way of cooking was considered the best one, the results showed that microwave and the conventional of cooking has made a huge difference. Through phenolic compounds analysis, the biggest concentration was founded on preparations which was applied high temperature. In contrast, the higher antioxidant action was founded in nature beetroot, showing how susceptible for changes its compounds are. This study emphasizes the beetroot consumption, mainly in a different cooking ways for numerous gastronomic preparations, intending an optimal vegetable usage, especially keeping up its bioactive compounds.

Keywords: Cooking, bioactive compounds, Beet

\section{INTRODUÇÃO}

A Beta vulgaris ou beterraba, trata-se de uma raiz olerícula, que pode ser consumida na forma crua, em sucos e diversos métodos de cocção. Ela é constituída de quatro variedades: Açucareira, Forrageira e Hortícola (Boletim técnico IAC; 2011). Teve seu consumo acentuado na última década, para o uso industrial, conservas e produtos infantis. É rica em sais minerais, vitaminas A, C, B1, B2, potássio, cobre e zinco, além disto, agrega grande importância para o sistema imunológico do consumidor. Dentre todos os benefícios do consumo, encontra-se a redução da pressão arterial. Possui nitrito, Ihe trazendo os benefícios do oxido nítrico, e propriedades antioxidantes, pela presença de compostos bioativos, como betalaina, e em sua estrutura possui ferro e ácido fólico, nutriente muito importante e essencial para a formação do feto, recomendado à gestantes e pessoas que passam por grande perda de peso (NATHALIE, 2010).

Segundo Gonçalves (2012), o efeito antioxidante se dá pela presença de ligações duplas conjugadas, e grupos de anéis aromáticos, aonde ocorre a estabilização agindo como doadora de elétrons ou hidrogênio para radicais livres. A betalaina é um composto nitrogenado, colorido e solúvel em água, localizado no vacúolo das plantas. As betalaínas, betanina e indicaxantina são referenciadas na proteção de LDL-colesterol contra ações oxidativas. Sua grande diferença é representar uma classe de antioxidante cationizados, com atividades antivirais, antimicrobianas e antiradical, é considerado um dos 10 anti-oxidantes mais potentes existentes, juntamente com seu efeito contra os radicais livres e prevenção de alguns tipos de cancer, como os de pele e fígado. Ocorre a conversão da $L$ tirosina para $o$ ácido betalâmico, conjugado juntamente com um aminoácido, ou amina, sendo uma das influenciadoras do seu grande poder antioxidante. Apesar dos inúmeros estudos, ainda não foi possível mensurar níveis referenciados de valores máximos a serem consumidos (ROSILANE, 2012).

Reshmi (2012) traz que, a beterraba possui uma cor característica vermelha arroxeada, proveniente da Betalaína, seu principal pigmento, que deriva do metabolismo secundário. Também, há sub pigmentos existentes como; Betacianinas vermelhas, que pode ser dividia em mais quatro subdivisões, são elas: betanina, amarantina, gonfrenina e bougainvillea, e as Betaxantinas amarelas. Sendo que em sua estrutura a divisão varia entre $75-95 \%$ de betacianina (betanina) e aproximadamente $95 \%$ de betaxantina (vulgaxantina I). Além disso, por trazer uma cor característica possui variados modos de aplicações, uma vez que há o uso crescente nas indústrias como corante, em gelatinas, sobremesas, bebidas, podendo 
também ser utilizada sua água de fervura em muitas receitas, bolos e sucos para se trazer cor e utilizar os benefícios nela contidas, mesmo havendo degradação das betalainas em relação a altas temperaturas, e exposição a luz (OLIVEIRA, 2017. CASTELLAR, 2003).

Os métodos de cocção utilizados nas cozinhas, se dividem em 3 grandes princípios, são eles a condução, a qual é feita com calor seco, empregado em chapas de calor. O calor úmido, a que se refere a cozinhar com emprego de agua e vapor nos alimentos, se denominando convecção. E radiação, utilizada em micro-ondas e em fornos para assar, aonde não possui contato direto com o alimento. O principal objetivo destes métodos é melhorar e manter o valor nutritivo, aumentar a digestibilidade, modificar a textura e a estrutura, melhorar a palatabilidade, e atuar na diminuição de organismos patológicos no qual podem a vir prejudicar o alimento (PHILLIPI, 2006).

Conforme Barbosa (2001) nas últimas duas décadas o micro-ondas ganhou espaço nas cozinhas, vindo a fazer parte nas maiorias dos lares, onde a sua maior vantagem é o menor tempo ao qual deve ser empregado ao alimento para sua preparação. Ele utiliza o método de cocção por radiação aderido ao calor seco, possuindo em sua estrutura um magnetron, o qual converte energia elétrica em microondas, gerando excitação das moléculas, aquecendo o alimento de dentro para fora sem contato direto, variando sua potência em relação ao tempo para uma uniformidade em seu calor empregado.

Já a fritadeira elétrica popularmente chamada de air-fryer, de acordo com o inventor Chad S. Erickson, que desenvolveu a base da tecnologia em 1989, se trata de uma "fritadeira" sem óleo, aonde possui uma resistência que gera o calor empregado e uma hélice que distribui o aquecimento ventilando pela superfície do alimento em altas temperaturas. Chegou ao brasil em 2011, mas ainda possui poucos estudos na área.

A preparação em calor úmido por convecção, é feita pela distribuição homogênea de temperatura no alimento pela difusão de zonas mais quentes on de a energia está em alta concentração, para as zonas mais frias, onde a energia é baixa, sendo este meio por cozimento mais utilizado para vegetais (BRENNAN et al, 1980).

Com base no exposto acima, o presente estudo, teve como objetivo avaliar a preservação dos antioxidantes presentes na beterraba após serem submetidos a cocção por meio de Air-fryer, Micro-ondas e Cozimento em água, assim como análise centesimal e de compostos bioativos, e análise sensorial para avaliar qual a preferência de consumo.

\section{METODOLOGIA}

O presente trabalho se trata de uma pesquisa do gênero de comparativa e qualitativa, na qual foi aprovado pelo comitê de ética em uma faculdade particular de Cascavel - PR, a qual foi realizada com parceria a uma universidade tecnológica federal do paraná.

\subsection{PREPARAÇÃO E COLETA DA AMOSTRA}

Foram utilizadas Beterrabas provenientes do comércio na cidade de Toledo, a primeira etapa foi fazer a higienização em água corrente, e escovada para retirada de sujidades. Somente após foi dado início ao processo de pré-preparo, e posterior análises.

A limpeza e preparação foi elaborada no Laboratório de nutrição da faculdade em estudo, no qual foi seguido normas de higiene e preparo de alimentos de acordo 
com a resolução RDC no 216/04, e boas práticas de manipulação. Como o principal objetivo da avaliação sensorial foi avaliar a aceitabilidade frente aos diversos meios de cocção, foi utilizado apenas o sal em 1\% a cada amostra da beterraba.

Tabela 1. Organograma da análise

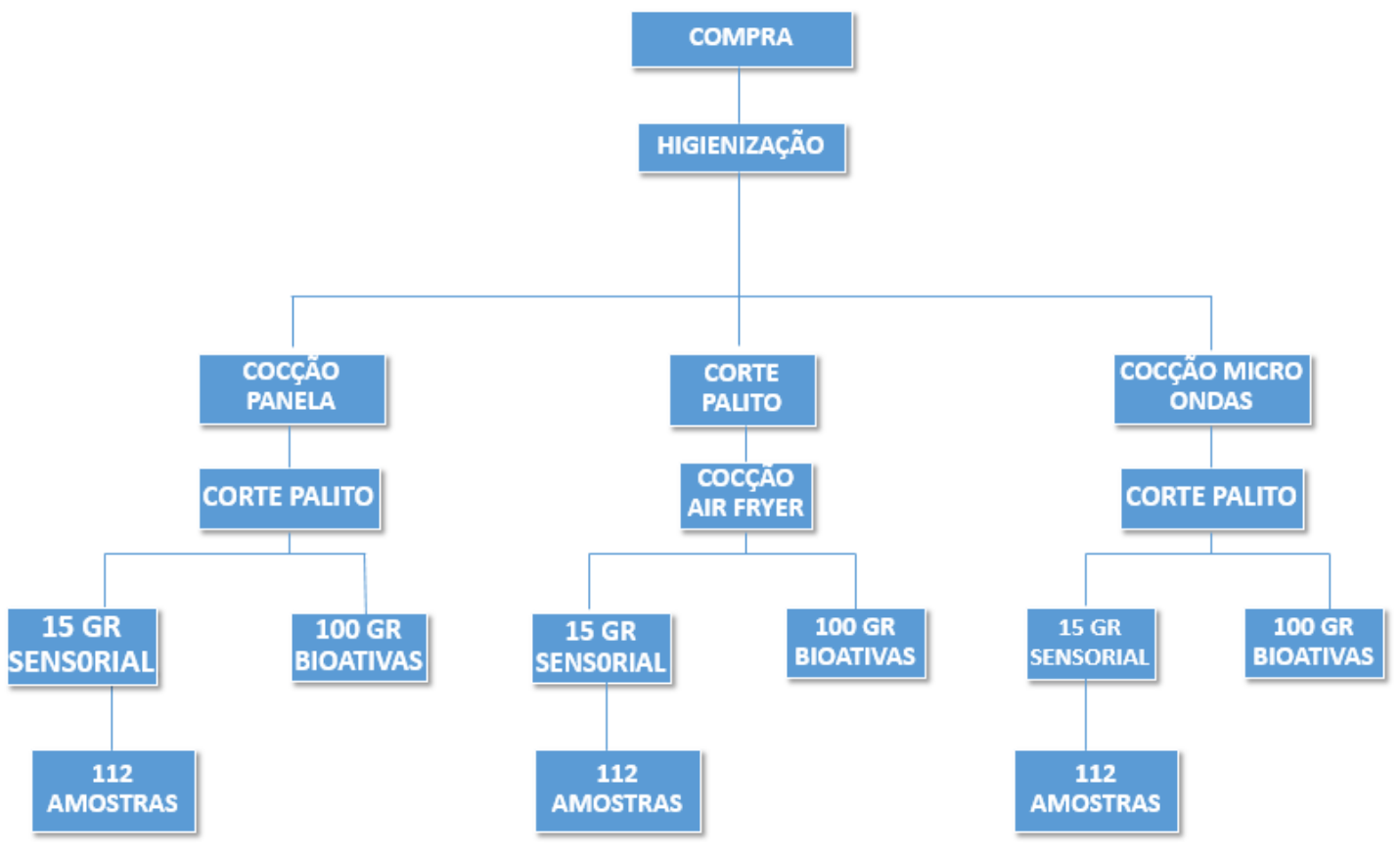

\subsection{MÉTODOS DE COCÇÃO}

Os 3 métodos de cocção e as interferências que cada meio provoca no alimento foram avaliadas através de micro-ondas modelo crisp - jet defrost 38 litros da Brastemp $\AA$, utilizado a Air Fryer Mondial AF-03® de 2,7 litros, e o cozimento em uma panela de Inox, redonda, em um fogão industrial da marca Steel ${ }^{\circledR}$ de 6 fogareiros. Os dados como tempo de preparação, potência do processo foram coletadas.

Foram elaboradas 3 preparações seguindo o seguinte padrão: Cocção em Micro-ondas sendo denominadas com o número 1, em Air-fryer com o número 2, e a Cocção em panela como 3 , sendo totalizadas 336 amostras (112 de cada), tendo seu tempo de preparo monitorado para obter uma uniformidade em todas as preparações, a beterraba foi servida em amostras de 15 gramas, após a cocção das análises foi 
retirado $100 \mathrm{Gr}$, separadas e armazenadas em embalagens a vácuo metalizadas, e identificadas, após foram congeladas em um congelador em temperaturas - 2 a - 15 para as avaliações de Compostos fenólicos.

\subsubsection{Micro-ondas}

As amostras foram higienizadas em agua corrente para retirada das sujidades, e logo após cocçionadas inteiras, por 17 minutos em potência máxima, após este processo, foram descascadas e cortadas com o auxílio de um cortador de legumes em forma palito.

\subsubsection{Air-fryer}

As amostras foram higienizadas em agua corrente para retirada das sujidades, descascadas e cortadas a mão em forma de palito, e após cocçionadas em potência máxima por 45 minutos.

\subsubsection{Cocção na panela}

As amostras foram higienizadas em agua corrente para retirada das sujidades, e logo após cocçionadas inteiras, em fogo alto por 40 minutos, posteriormente descascada e cortada com o auxílio de um cortador de legumes em forma palito.

\subsection{ANÁLISE SENSORIAL}

Os participantes foram orientados a ler e preencher o termo de consentimento livre esclarecido, concordando com a participação no estudo. Foram orientados quanto a individualidade das amostras, e a codificação com 3 numerais, no qual foi entregue o teste de ordenação de preferência, para o preenchimento após o consumo conforme o paladar do consumidor, com os campos primeira, onde é preenchido a amostra de maior preferência, segunda, para a de preferência mediana, e terceira, para preferência inferior as outras amostras, para posterior comparação dos métodos. Em seguida encaminhados a cabines individuais, sendo entregues as 3 amostras aleatoriamente, e ao mesmo tempo, juntamente foi entregue talheres de plástico, guardanapo e agua, orientandos a consumir após o consumo de cada amostra para limpeza do palato.

\subsection{ANALISE ESTATISTICA}

Para a tabulação dos dados da sensorial, foi seguido o método de ordenação bilateral, com critério de teste de preferência proposto por Friedman, conforme a formula a seguir

$$
\mathrm{F}=\frac{12}{A v^{*} \mathrm{t}^{*}(\mathrm{t}+1)} *\left(\mathrm{~S} 1^{2}+\mathrm{S} 2^{2}+\mathrm{S} 3^{2}\right)-3^{*} \mathrm{Av}{ }^{*}(\mathrm{t}+1)
$$

$A v=$ Número de avaliadores

$\mathrm{t}=$ Número de amostras

$\mathrm{S} 1$ = Soma das ordens atribuidas ao tratamento

\subsection{POPULAÇÃO DA AMOSTRA}

O grupo de provadores foi constituído por indivíduos maiores de 18 anos, em um centro universitário na cidade de cascavel localizado no paraná, no qual tiveram sua aceitação condicionada e autorizada devida a assinatura no Termo de Consentimento Livre e Esclarecido (TCLE). 


\subsection{ANÁLISE DE COMPOSTOS FENÓLICOS E ANTIOXIDANTES}

Logo após a cocção, foi reservado amostras de $400 \mathrm{Gr}$, sendo $100 \mathrm{Gr}$ de cada método, e a amostra in natura, em sacos a vácuo metalizados, para não haver a incidência exacerbada de luz, e oxigênio nas amostras, onde foram encaminhadas para a análise da preservação e determinação de compostos fenólicos pelo método de Singleton e Rossi (1965), e de atividade antioxidante DPPH pelo método de Bondet (1997). Onde se obteve dados dos valores de concentração iniciais antes do preparo, para que seja realizada a sua comparação com os dados pós cocção. Para esta análise foi feita parceria com uma Universidade Tecnológica Federal, na cidade de Toledo - PR,

\section{RESULTADOS E DISCUSSÃO}

Através da análise sensorial realizada com 112 indivíduos não treinados, com critério de exclusão daqueles que possuíam alguma alergia ou aversão as preparações. De acordo com as tabelas 34 e 35 de (Dutcosky, 2013), verificou o valor tabelado de 29, na qual os valores que diferiram em maior ou igual ao do valor tabelado são significativamente diferentes entre si.

As análises da beterraba obtiveram o valor de 36,80 de acordo com a formula de Friedman, com uma relação de nível de significância de $5 \%$, na qual as amostras de cocção em micro ondas obteve o valor de 75 , e cozimento convencional de 95 , a airfryer tendo o valor 20, levando em consideração o valor tabelado de 29, sendo a amostra de aifryer se demonstrou inferior as demais amostras, de acordo com a gráfico abaixo.

Figura 01. Tabulação da análise sensorial

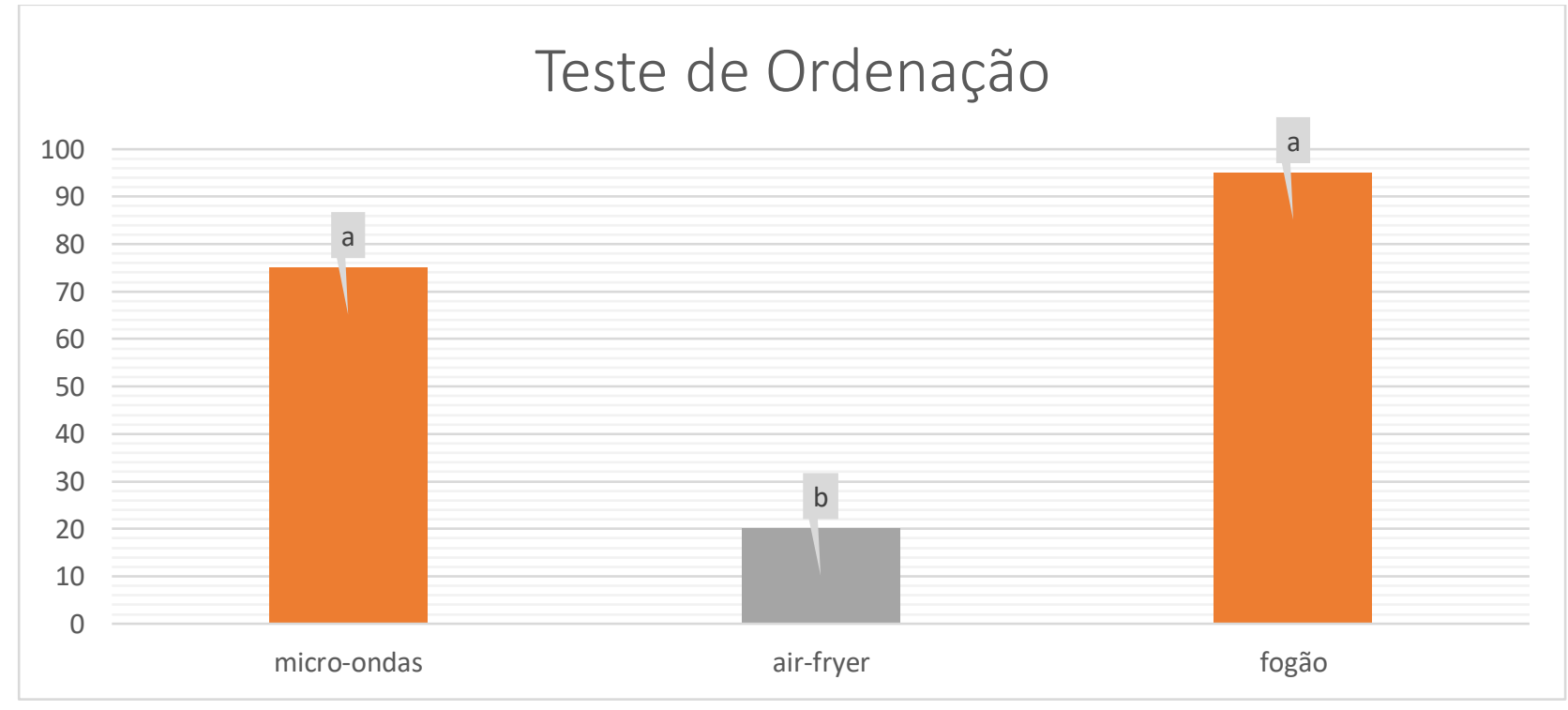

A cocção das amostras de micro-ondas e fogão não diferem estaticamente, recebendo a denominação com a letra a, demonstrando também que a amostra da air-fryer foi a que teve menos aceitabilidade em relação as outras amostras, denominada com a letra b. Segundo Carvalho et al., (2005), o tipo de corte, assim como os métodos de cocção podem alterar a percepção dos consumidores diante a produtos da mesma cultivar e do sistema de cultivo realizado, sendo fundamental para 
determinar a preferência de um produto a outro, proceder testes diferenciados quanto a estes critérios. A análise sensorial é em função das respostas passada pelos indivíduos, por meio dos próprios órgãos que utilizam, sendo os dos sentidos da visão, olfato, audição, tato e gosto, portanto, com esses sentidos, pode causar lembranças das memórias afetivas que envolva o alimento (INSTITUTO ADOLFO LUTZ, 2008).

As amostras da airfryer em comparação com as demais amostras, obteve um escurecimento de sua superfície devida a cocção realizada, sendo ocasionada pela presença de polifenol oxidases, (GONÇALVES et al, 2015), possuindo com uma estrutura mais firme e seca, devida a desidratação causada pelo processo, onde reflete uma mudança de cor reversível, a qual é mais acentuada quanto maior a perda de água, (VITTI et al., 2003) causando uma aparência envelhecida, com a redução da intensidade da coloração, e não atraente aos indivíduos, sendo uma das complicações de utilizar este método de cocção, juntamente com o longo período necessário para a realização da beterraba. As amostras de micro-ondas se demonstrou o processo mais rápido e prático para o dia a dia quando comparada com o cozimento convencional, pelo tempo que deve ser empregado a sua preparação. Demonstrando que não apenas o cozimento convencional pode ser aplicado no dia a dia, mas também a cocção pelo micro-ondas, variando os processos.

A análise dos compostos fenólicos das amostras seguindo o método de Singleton e Rossi (1965), nos demonstraram os compostos fenólicos totais da amostra. Sendo de grande importância, pois variados estudos tem demonstrado que são alguns dos principais responsáveis pela atividade antioxidante dos vegetais (TIVERON, 2010). Este método analisa estes compostos sem sua diferenciação entre as betacianinas e betaxantinas, e as suas demais subdivisões, tendo de acordo com o referenciado por Gonçalves et al (2015), que no cultivar de beterrabas vermelhas, seus valores variam entre $0,04-0,21 \%$ e $0,02-0,14 \%$, respectivamente, dependendo da forma do cultivar.

De acordo com o especificado nos 3 métodos de cocção e na amostra in natura, foi verificado a quantidade de fenóis totais de cada amostra individualizadas, tendo como base o ácido gálico nas análises, estas foram realizadas sucessivamente em triplicatas para uma homogeneização do resultado, obtendo as seguintes concentrações abaixo expressas no gráfico apresentado na figura 2.

Figura 02. Análise dos compostos fenólicos 


\section{COMPOSTOS FENÓLICOS}

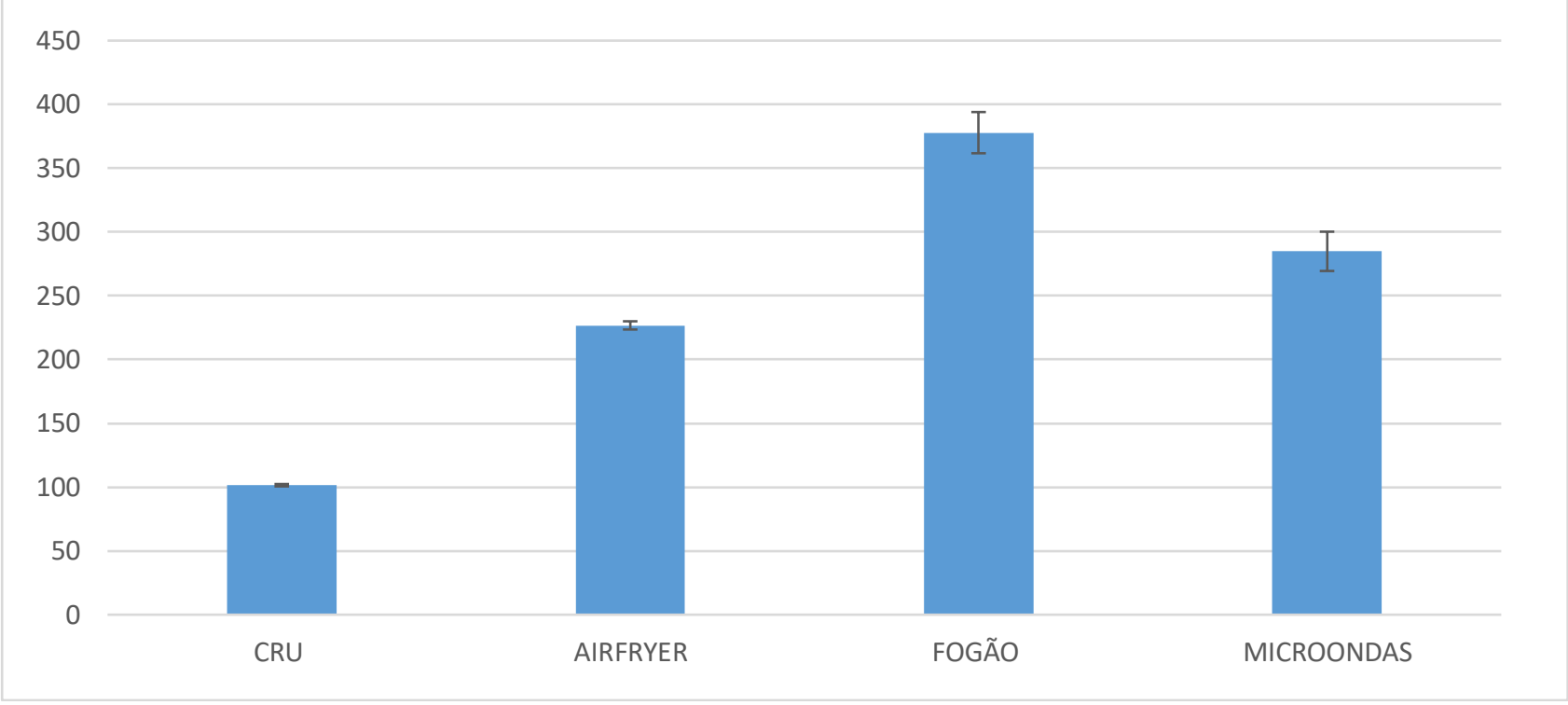

Os valores encontrados tiveram sua variável de desvio padrão calculadas para uma melhor análise crítica. Visualizando o gráfico vemos que o valor demonstrando na preparação crua foram menores quando comparadas as demais amostras, resultado causado pelo estresse desencadeado do corte durante o pré preparo, causando um extravasamento dos compostos fenólicos, por possuir sua localização na organela celular concentrada nos vacúolos, ao causar injurias mecânicas provenientes do corte realizado, se pode notar que danificam a membrana que envolve o vacúolo chamada de tonoplasto, e os plastídios, o que ocasiona o vazamento de fenóis (PICOLI et al (2010). Segundo Gobbo e Lopes (2007) alguns fatores como a sazonalidade, temperatura, disponibilidade hídrica, radiação ultravioleta, adição de nutrientes, poluição atmosférica, danos mecânicos e atividade de patógenos, influenciam em sua quantidade de fenóis nos vegetais.

A amostra realiza na air fryer demonstrou o valor abaixo as demais amostras cocçionadas devido a ter passado pela fase de corte antes da cocção, aumentando assim sua oxidação com as injurias causadas, e maior exposição ao meio, provocando uma diminuição nos compostos fenólicos presentes em sua estrutura (OLIVEIRA, 2017. CASTELLAR, 2003). Conforme o elucidado por Campos et al (2008), nos traz que a cocção facilita a extração de destes compostos, e que os tratamentos térmicos menos severos, como temperatura menores e por um período mais curto, podem ser benéficas em alguns casos, devido ao aumento no teor de carotenoides existentes, pode ser atribuído a uma facilidade de extração pela temperatura, podendo além de inativar enzimas oxidativas, desnaturar complexos carotenoide-proteína existentes nas células vegetais.

Conforme a amostra realizada por cozimento convencional no fogão com pouca água, e micro ondas, se demonstraram serem as que possuem a maior quantidade de compostos fenólicos, pois foram submetidas a cocção inteiras e com casca, assim proporcionando uma menor perda dos fenóis em suas estruturas (Gráfico 02). Nos mostrando que o melhor método no qual possui uma maior quantidade de compostos fenólicos expressos na estrutura, são os que passam por influência de temperaturas com a beterraba inteira e com casca. Resultado proveniente da sua constituição de sua estrutura possuindo o licopeno, o qual tem sua maior ativação quando empregado 
calor conforme especificado por Rao et al (2002), e vários compostos bioativos. Ao mesmo tempo que o estudo de Oliveira, (2017), demonstra possuir a diminuição de betalainas com emprego de calor, assim possuindo compostos que podem aumentar e diminuir com o tratamento térmico, como as antocianinas de seus pigmentos, o qual podem ter sido aumentadas durante as análises (TIVERON, 2010). Estas antocianinas podem chegar ao dobro do potencial antioxidante dos antioxidantes comerciais como vitamina $E$, e uma melhor atividade o butihidroxanisol $(\mathrm{BHA})$ e o butilhodroxitolueno (BHT) (MACHADO et al, 2013).

Entretanto outra análise realizada de compostos antioxidantes pelo método de $\mathrm{DPPH}$, a qual já vem sendo difundida desde meados do século 50 , tinha como principal objetivo descobrir a capacidade de produtos naturais em serem doadores de hidrogênio e elétrons, e com o passar dos tempos, em determinar o potencial antioxidante em compostos fenólicos individuais de alimentos (ROGINSKY, LISSI, 2005). Consiste em avaliar a atividade antirradicalar, pois o método utiliza 2,2-difenil1-picrilhidrazil (DPPH) como radical livre, e mede a mudança de sua coloração purpura para amarela, sendo a diminuição do radical livre medida pela absorbância. Medindo a capacidade da amostra em reduzir o DPPH, ou seja, evitar a sua oxidação, então a porção restante é proporcional a concentração de antioxidantes (BONDET et al, 1997), A variação demonstrada no gráfico abaixo, avalia a capacidade de o composto antioxidante doar um elétron ou hidrogenio para o composto oxidante, e alcançar o IC 50, valor que o qual estima a concentração de antioxidante para inibir $50 \%$ do radical DPPH (BOROSKL et al, 2015).

\section{ATIVIDADE ANTIOXIDANTE BETERRABA - DPPH}

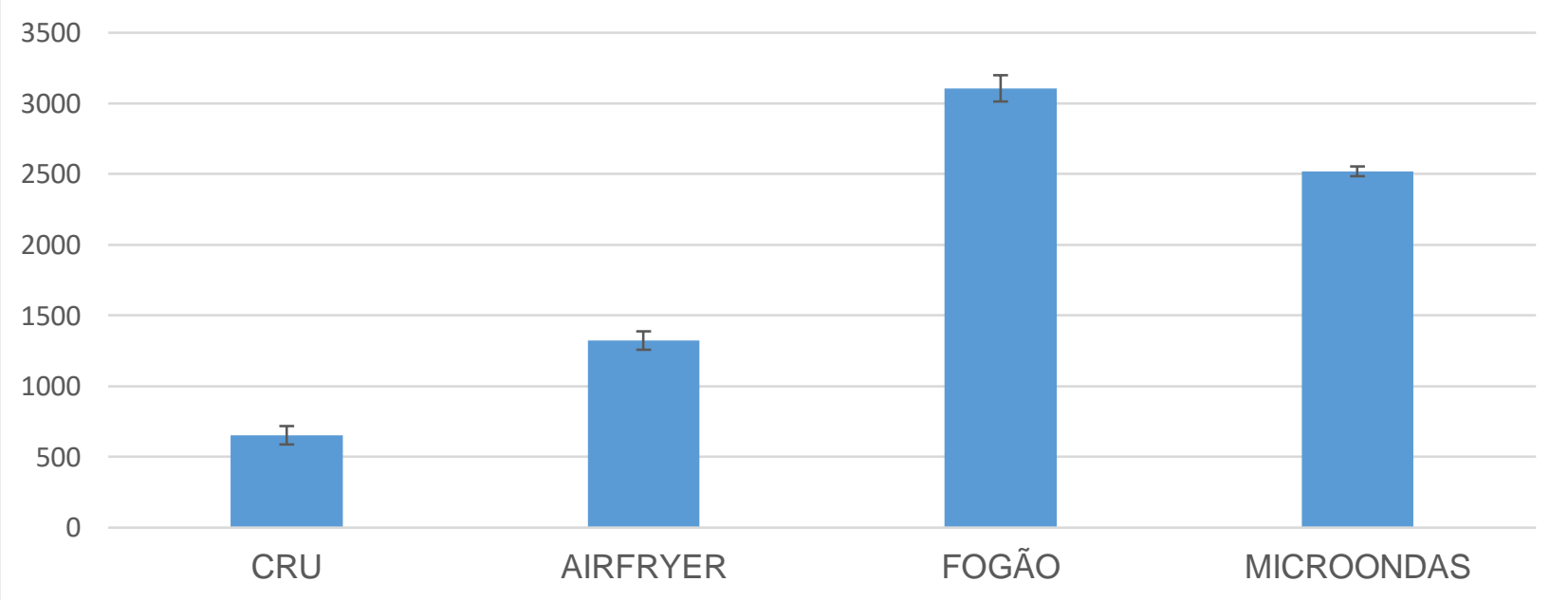

Figura 3. Atividade antioxidante da beterraba - DPPH

Os valores variaram entre 653,33 a 3106,67 . A análise da beterraba crua demonstrou possuir uma maior capacidade de estabilizar um radical livre, a amostra da airfryer por sua característica de desidratação por calor seco, manteve uma quantidade maior de fator antioxidante ao radical livre, quando comparado aos outros métodos de cocção, sendo que a alta temperatura possui influência sobre a quantidade de betalaina Volp et al (2009). As amostras realizadas por meio convencional, resultou em uma maior perda, podendo ser pela oxidação no pré preparo e cocção. Mas levando em consideração que a beterraba possui outros compostos bioativos, este valor expressa a atividade antioxidante em geral do extrato. De acordo com Tiveron (2010) foi demonstrado que as antocianinas presentes no 
pigmento e suas formas agliconas são compostos bioativos, entre todas as funções fisiológicas, trazem consigo a atividade antioxidante, a qual podem ter sido modificadas com o processo.

Conforme o estudo de Melo et al (2009), descreve que os tratamentos térmicos em hortaliças ocorre diversas alterações na capacidade antioxidante, sendo variável os resultados, pois a cocção pode tanto não alterar, aumentar ou reduzir a ação antioxidante do alimento. No caso de comparação da ação antioxidante de hortaliças cruas e cozidas, realizadas neste estudo, deve avaliar em o teor dos compostos bioativos, em termos quantitativos e qualitativos, pois o mesmo varia em função de fatores intrínsecos (cultivar, variedade, estádio de maturação) e extrínsecos (condições climáticas, disponibilidade hídrica, radiação ultravioleta, adição de nutrientes, poluição atmosférica, danos mecânicos e atividade de patógenos). Assim, a retenção destes constituintes em hortaliças cozidas pode estar relacionada com 0 meio.

\section{CONSIDERAÇÕES FINAIS}

Considerando que as amostras de beterraba foram compradas em um mercado local, e não se obteve informações de sua forma de cultivo, as interferências extrínsecas e intrínsecas desconhecidas, e que diferenças nos teores de nutrientes, coloração, e compostos bioativas, variam de uma raiz para outra, os resultados divergiram de acordo com os diversos processos realizados.

Os resultados obtidos demonstraram que nem sempre as maiores quantidades de compostos fenólicos, possuem a melhor atividade antioxidante quando avaliado sobre os compostos fenólicos totais sobre o método de radical livre DPPH, o qual obteve uma melhor ação antirradicalar com uma baixa quantidade fenóis, diante de um alimento complexo com vários constituintes de carotenoides, flavonoides, antocianinas, e compostos fenólicos, com diferentes formas de reagir ao tratamento térmico, ressaltando a influência de antioxidantes não fenólicos e sua influência nos radicais livres, necessitando de uma avaliação individualista de cada composto para uma melhor elucidação das formas de cocção em sua interferência.

O consumo da beterraba em suas diferentes formas de cocção se deu conforme a maior preferência em suas preparações em micro-ondas e cozimento convencional na panela, demonstrando que a caracterização da aparência da amostra proveniente da airfryer não foi convidativa aos provadores, assim demonstrando que sua apresentação visual não foi atrativa ao público. Comprovando que a memória afetiva é um fator determinante, para a aceitação ou não dos métodos.

Concluindo que diante do presente estudo, o consumo da beterraba deve ser em suas diferentes formas culinárias, onde possamos aproveitar o benefício nela contida de forma integral, variando os métodos de cocção.

\section{REFERÊNCIAS}

AMAYA FARFAN J., DOMENE S. M. A, PADOVANI R. M. Síntese comentada das novas propostas sobre recomendações nutricionais para antioxidantes. Revista de Nutrição. v. 14, n 2, p 71-8, 2001. 
BARBOZA, A. C. R. N. et al. Aquecimento em forno de microondas/desenvolvimento de alguns conceitos fundamentais. Química Nova, São Paulo, v. 24, n. 6, p. 901-904, nov./dez. 2001.

BONDET, V.; BRAND-WILLIAMS, W.; BERSET, C. Kinetics and Mechanisms of Antioxidant Activity using the DPPH• Free Radical Method. Lebensmittel-Wissenschaft-und-Technologie, v. 30, p. 609-615, 1997

BRENNN, J.G.; BTTERS, J.R.; COWELL, N.D.; LILLY A.E.V. As operações de engenharia dos alimentos. Zaragoza: Editorial Acribia, 1980b. p.518-524

CAMPOS, M. F. et al. Determinação dos teores de vitamina C em hortaliças minimamente processadas. Alimentos e Nutrição, Araraquara, v. 19, n. 3, p. 329335, 2008.

CARVALHO, A.M.; JUNQUEIRA, A.M.R.; VIEIRA, J.V.; BOTELHO, R. Análise sensorial de genótipos de cenoura cultivados em sistema orgânico e convencional. Horticultura Brasileira, v.23, n.3, p.805-809, 2005.

CASTELLAR, R., OBON, J.M., ALACID, M., FERNANDEZ-LOPEZ, J.A. Propriedades de cor e estabilidade de betacianinas das frutas Opuntia. J. Agric. Food Chem. v. 51 p. 2772-2776, 2003.

FERREIRA, N. A.; LOPES, S. B.; MORRETI, C. L.; MATTOS, L. M. Processamento Minimo de Mini Beterraba, Comunicado Técnico, EMBRAPA, dezembro, 2009 Brasilia, DF.

FERREIRA, N. C. Aproveitamento de resíduos do processamento mínimo de Beterraba: elaboração de produtos tecnologicos, avaliação sensorial, físicoquimica e de compostos funcionais. Brasilia, 2010.

GONÇALVES, L. C. P., Betalaínas: semissíntese, capacidade antirradicalar e aplicação como sondas em sistemas biológicos. Universidade Federal do ABC, Santo André, 2012.

GONÇALVES, L. C. P.; MARCATO, A. C.; RODRIGUES, A. C. B.; PAGANO, A. P. E.; FREITAS, B. C.; MACHADO, C. O.; NAKASHIMA, K. K.; ESTEVES, L. C.; LOPES, N. B.; BASTOS, E. L. Betalaínas: das Cores das Beterrabas à Fluorescência das Flores. Rev. Virtual Quim. V.7, n.1, p. 292-309, 2015.

LIZANDRA C. P. OLIVEIRA, Utilização de polpa e resíduos de beterraba para aproveitamento tecnológico na formulação de iogurte concentrado. Instituto Federal Mato Grosso, Cuiabá, 2017.

LUGASI, A.; BIRO, L.; HOVARIEA, J.; SAGIA, C. V.; BRANDTB, S. Lycopene content of foods and lycopene intake in two groups of the Hungarian population. Nutrition Research n. 23, v. 8, p. 1035-1044, 2003.

MORITZ, B.; TRAMONTE, V. L. C.; Biodisponibilidade do Licopeno, Revista de Nutrição. V.19, n2, p265-273, , 2006 
PHILLIPI, S. T. Nutrição e técnica dietética. 2. ed. rev. e atual. Barueri, SP: Manole, 2b006. p. 45.

PICOLI, A. A.; FARIA, D. B.; JOMORI, M. L. L.; KLUGE, R. A. Avaliação de biorreguladores no metabolismo secundário de beterrabas inteiras e minimamente processadas Bragantia, vol. 69, núm. 4, 2010, pp. 983-988 Instituto Agronômico de Campinas Campinas, Brasil.

PIMENTEL, C. V. M. B.; FRANCKI, V.M.; GOLLUCKE, A. P. B. Alimentos Funcionais, Introdução às principais substancias bioativas em alimentos, Livraria Verela, São Paulo, 2005

RAO, A.V., SHEN, H. Efeito do consumo de licopeno em baixas doses na biodisponibilidade do licopeno e no estresse oxidativo. Nutr Res, v. 22, p. 1125-31, 2002

RESHMI, S. K; ARAVINDHAN, K. M; DEVI, P.S. O efeito da temperatura e ph na estabilidade de pigmentos de betacianina em frutas de basella alba. Asian jornal farmacêutico, v.5, n.4, p. 107-110, 2012.

SILVA, P. T.; LOPES, M. L. M.; VALENTE- MESQUITA, V. L. Efeito de diferentes processamentos sobre o teor de ácido ascórbico em suco de laranja utilizado na elaboração de bolo, pudim e geléia. Revista de Tecnologia em Alimentos. v.26, n.3, p.678-682, 2006.

SINGLETON, V. L.; ROSSI, J. A. Colorimetric of total phenolics with phosphomolybdicphosphotungstic acid reagents. American Journal of Enology and Viticulture, v. 16, n.3, p.144-146, 1965

SOUZA, R.M. Corantes naturais alimentícios e seus benefícios à saúde. UEZO, centro universitário estadual da zona oeste, Rio de Janeiro, 2012.

TIVELLI, S. W.; FACTOR, T. L.; TERAMOTO, J. R. S.; FABRI, E. G.; MORAES, A. R. A.; TRANI. P. E.; MAY, A. Beterraba: do Plantio à Comercialização. Boletim técnico IAC, 210, Campinas, novembro de 2011.

TIVERON, A. P. Atividade antioxidante e composição fenólica de legumes e verduras consumidas no Brasil. Dissertação mestrado, Escola superior de agricultura Luiz de Queiroz, Piraicicaba, 2010.

TORRES, G. F.; SALGADO, S. M.; LIVERA, A. V. S.; GUERRA, N. B. Efeito do processo hidrotérmico sobre o teor de fibra alimentar em hortaliças. Boletim CEPPA, v. 24, n. 2, p. 337-346, 2006.

VAN HET HOF K.H.; WEST, C.E.; WESTSTRATE, J.A.; HAUTVAST, J.G. Fatores dietéticos que afetam a biodisponibilidade de carotenóides. J Nutr. v.130, n.3, p. 5036, 2000. 
VITTI, M.C.D.; KLUGE, R.A.; YAMAMOTTO, L.K.; JACOMINO, A.P. Comportamento de beterrabas minimamente processadas em diferentes espessuras de corte. Horticultura Brasileira, v. 21, n. 4, p. 623-626, 2003.

VOLP, A. C. P.; RENHE, I. R. T.; STRINGUETA, P. C. Pigmentos Naturais Bioativos. Alimentos e Nutrição Araraquara v.20, n.1, p. 157-166, 2009. 